\title{
EFFECTS OF BIMONTHLY RAINFALL ON COCONUT YIELD IN THE LOW COUNTRY INTERMEDIATE ZONE (IL $)_{1}$ OF SRI LANKA
}

\author{
T S G Peiris and R R A Peries
}

Coconut Research Institute, Lunuwila, Sri Lanka.

\begin{abstract}
Coconut yields in Sri Lanka show considerable fluctuation between years mainly due to variation in the distributions of major climatic parameters such as rainfall, solar radiation and relative humidity. The effect of current weather is usually reflected on the yields of the following year. However, the degree of influence of these variables on coconut yield is yet unknown. An attempt was made to study the influence of intensity and distribution of rainfall in two-monthly sub-periods of the previous year on nut yield at Ratmalagara Estate in the Low Country Dry Intermediate Zone ( $75 \%$ annual rainfall probability $>1500$ ) of Sri Lanka. Rainfall during January/ February was found to be the most influential factor on the subsequent years total yield and the yield increased with increasing rainfall. The rainfall during March/April had a similar effect where around $400 \mathrm{~mm}$ was found to be sufficient. The high intensity of rainfall during May/August adversely affected the crop, where amount in excess of $450 \mathrm{~mm}$ was not utilized to increase the yield. The impact of rain during July/August was minimal. High rainfall during September/ October and November/December had a depressing effect on yield, and this was very significant with respect to the November/December rainfall. A multiple regression model with $R=89 \%$ was developed using a combination of some parameters of bimonthly rainfall which would be useful in determining the potential yield and to explain yield fluctuation between years to a certain degree.
\end{abstract}

\section{INTRODUCTION}

The coconut palm generally produces one mature bunch regularly every month. Each bunch goes through a cycle of development lasting about $\mathbf{4 6}$ months before it is ready for harvest. Development of nuts takes place during the last twelve months after opening of the inflorescence (Child, 1974). This period as well as certain periods prior to this are very sensitive to major climatic elements such as rainfall, solar radiation, and atmospheric relative humidity. Though a maturc bunch can be harvested monthly, the crop is usually collected at bimonthly intervals (six picks a year) for convenience, and this is generally done in January/February, March/April, May/June, July/August, September/October and November/December. Coconut is a perennial crop, showing a high degree of tolerance to sub-optimal climatic factors. A well-distributed mean annual rainfall of between 1,500-2,000 $\mathrm{mm}$ is considered to be favourable for cultivation of coconut. In addition, the soil type within a given agroclimatic zone, is also important.

Peiris (1989) showed that the yield fluctuation within years in the Dry Intermediate Zone of Sri Lanka was seasonal. However, the yield fluctuation between years was very complex. When nutrients are non limiting, the yield variation is controlled mainly by the distribution of major 
climatic variables such as rainfall, solar radiatioin (SR) and relative humidity (RH) during the previous year. Though $S R$ and $R H$ are not linear functions of rainfall, no studies have been carried out to identify the impact of these external variables on coconut yields. A study on the influence of rainfall on yield has also been difficult due to erratic variation in rainfall.

In Trinidad, Smith (1966) reported a strong correlation between yield and cumulative rainfall over a period of 29 months prior to harvest. Abeywardena (1968), in his study of the yield at Bandirippuwa Estate (BE) in the Low Country Intermediate Zone ( $\mathrm{IL}_{\mathrm{d}}$ ) of Sri Lanka (the mean and the $75 \%$ probability of the annual rainfall during the 31 years period $1958-1988$ are $1909.8 \mathrm{~mm}$ and $2066.9 \mathrm{~mm}$, respectively), showed that rainfall during the period May to August of the previous year was more influential on yield variation than rainfall during the period January to April or September to December. Prasada Rao (1986) reported that both high rainfall during the months of June, July and August as well as the absence of post-monsoon and pre-monsoon showers adversely affected the subsequent year's nut yield in Kerala, India. Studies in Thailand by Dootson et al. (1989) have shown that the mean monthly temperature, number of rainy days, sunshine hours and evaporation were the factors largely correlated with yield. Prasada Rao (1991) has indicated the necessity of further studies of the climatic requirements of coconut. These studies revealed that the crop response to major climatic variables, specially rainfall had to be further investigated and their effect should be based on distribution of rainfall and also on the soil type. An identification of the degree of influence of the climatic factors for a given location would be useful in crop-simulation models and to understand the physiological phenomena of the palm. Further, such an analysis would assist in short-term yield forecasting and consequently in determining the potential yield in a given agro-climatic region.

In view of the above, the emphasis of the present study was to ascertain the intensity of influence of rainfall during two monthly periods of the year on annual nut yield of coconut in the Dry Intermediate Zone of Sri Lanka.

\section{MATERIALS AND METHODS}

The crop data from 1969 to 1989 at Ratmalagara Estate (RE) at the Coconut Research Institute (CRI) located in the Low Country Intermediate Zone (ILI) in Sri Lanka and daily rainfall records from 1958-1988 measured from the rain gauge maintained at the agro-meteorological statioin at the site were used in this study. The mean annual yield per hectare ( $158 \mathrm{palms} / \mathrm{ha})$ over a 21 year period was 10,132 nuts, with the maximum of 13,210 (1971) and a minimum of 5,898 (1980).

The mean and the 75 percent probability of annual rainfall over the period of 31 years were $1559.7 \mathrm{~mm}$ and $1685.0 \mathrm{~mm}$ respectively with a minimum of $1033.4 \mathrm{~mm}$ (1983) and a maximum of $2390.3 \mathrm{~mm}$ (1984). The number of rainy days $(>0.5 \mathrm{~mm}$ ) per annum over the same period was 112 with a minimum value of 68 in 1967 and a maximum of 144 in 1961. The annual minimum and maximum mean temperature during the period from 1969 to 1990 were $23.3^{\circ} \mathrm{C}(\mathrm{sd}= \pm 1.6$ ) and $30.1^{\circ} \mathrm{C}(s d= \pm 0.9)$ respectively. The soil was sandy loam overlying lateritie gravels.

\section{RESULTS AND DISCUSSION}

\section{Degree of Influence of Total Rainfall}

The relationship between the annual yield vs time over the 21 years did not exhibit a seasonal or cyclic pattern. A graph representing annual yield and the cumulative rainfall in the previous year 
also did not show a systematic correlation and it was therefore not possible to detect any quantitative relationship between yield and annual rainfall. The correlation coefficients between yield and cumulative rainfall (and other parameters of rainfall) during the harvesting year, or preceding year, or of two years prior to it, or their combinations were low. It indicated that the parameters of annual rainfall alone were not adequate to explain the temporal variation in yield.

\section{Degree of Influence of Four Monthly Rainfall Perioids}

Let JA (4), MA (4) and SD (4) denote the total rainfall during January/April, May/August and September/December of the preceding year of the harvest. The correlation coefficients $(r)$ between yield and cumulative rainfall of four-monthly sub periods were calculated for seven groups of 15 consecutive years from 1969 to 1989. Such groupings were considered to result in a more unbiased estimate of $(r)$ rather than considering all years at once. The mean correlation coefficient and the mean coefficient of determination presented hereafter are referred to as mean value over the seven yearly-groups and are denoted by $r_{m}$ and $R_{m}^{2}$ respectively. The $r$ and $r_{m}$ values for the four month sub-periods are given in Tablel.

Table 1. Values of $r$ Between Yield and Four Monthly Rainfall in the Year Prior to Harvest

\begin{tabular}{llll}
\hline $\begin{array}{l}\text { Year } \\
\text { group }\end{array}$ & $\begin{array}{l}\text { JA (4) } \\
\text { Jan/Apr }\end{array}$ & $\begin{array}{l}\text { MA (4) } \\
\text { May/Aug }\end{array}$ & $\begin{array}{l}\text { SD (4) } \\
\text { Sep/Dec }\end{array}$ \\
\hline $69-83$ & 0.480 & 0.359 & $-0.632^{* *}$ \\
$70-84$ & $0.516^{*}$ & 0.393 & $-0.509^{*}$ \\
$71-85$ & $0.558^{*}$ & 0.366 & -0.473 \\
$72-86$ & $0.543^{*}$ & 0.184 & $-0.601^{*}$ \\
$73-87$ & $0.610^{* *}$ & 0.219 & -0.480 \\
$74-88$ & $0.601^{* *}$ & 0.182 & -0.399 \\
$75-89$ & $0.539^{*}$ & 0.212 & -0.423 \\
mean & $0.550^{*}$ & 0.274 & -0.502 \\
& & &
\end{tabular}

\section{January/April [JA (4)]}

The $\mathrm{r}$ values for January /April were all positive and statistically significant at the $5 \%$ level except one which was also near significance at the $5 \%$ level. The $r_{m}$ was $0.550 *$ and the $R_{m}^{2}$ in the linear model was 30.4 These results revealed that the rainfall during this period was favourable towards increasing yield. Inclusion of JA (4) ${ }^{2}$ into the linear models fitted to seven yearly-groups did not improve the $\mathbf{R}^{2}$ indicating that the palms had the potential for higher yield with higher rainfall during the first quarter of the year.

\section{May/August [MJ (4)]}

The minimum $r_{m}$ was observed during May/August and in fact, $r$ values were lowest in all seven groups. By adding MA (4) ${ }^{2}$ into the linear models the $\mathbf{R}^{2}$ was significantly improved in all groups and both parameters in the quadratic models were either significant at the $5 \%$ or $10 \%$ level. This reveals that the crop response to rainfall during May/August was quadratic and rainfall above the maximum point of the quadratic model was not utilized by the palms. The maximum points obtained in the quadratic models fitted for seven yearly-groups mentioned above were in the range 
of 509 to $545 \mathrm{~mm}$. Therefore it can be concluded that the optimum cumulative precipitation the palms required during May/August was around $550 \mathrm{~mm}$.

\section{September/December [SD (4)]}

The $r$ values during this period were all negative and were statistically significant either at $5 \%$ or $10 \%$ level. The $r_{m}$ was -0.502 . Addition of $S D(4)^{2}$ into the linear models slightly improved $\mathrm{R}^{2}$, but neither the F-values nor the parameters of the quadratic model were significant. This indicates the likelihood of harmful effects due to heavy rainfall during September/December, when other external factors required by the palms may not be at optimum level.

The correlations observed for the above three sub-periods by Abeywardene (1968), using 30 years crop data in a single analysis were $0.253,0.542$ and -0.0452 at $B E$. This correlation structure was different from the observations in this study at RE, where the corresponding values were $0.550,0.274$ and -0.502 . Of course, as shown above, these two estates are located in two different agroclimatic zones. However, it is important to observe that the correlation with rainfall in the last quarter of the year was negative in both regions, even though the value at $B E$ was extremely low. The magnitude of the correlations obtained for January/April and May/August at RE was of similar order to the values obtained for May/August and January/April respectively, at BE. These results provide more thoughts for future studies. Due to the complex floral biology of coconut, it is difficult to attribute these responses quantitatively to any one or a set of variables. However, as a preliminary investigation it was considered appropriate to study the effect of rainfall of two monthly sub-periods.

\section{DISTRIBUTION OF BI-MONTHLY RAINFALL}

The monthly rainfall pattern in this area is bimodel. One peak is due to South-West monsoon rains during May/June ("Yala" season) and the other due to North-East monsoon rains during October/November("Maha" season). Peiris and Seneviratne (1989) have shown that the probability of rain occurring in "Yala" and "Maha" on or before $2^{\text {nd }}$ of May and $18^{\text {th }}$ October, respectively was 0.50. It was also shown that there was no cyclic pattern in the rainfall.

The average contribution of the six picks to the total yield in the 21 years period in this region was $12.1 \%, 16.9 \%, 20.7 \%, 16.2 \%$ and $11.9 \%$ respectively. A similar trend has been observed at BE by Abeywardena and Fernando (1963). The impact of weather on the six picks would not be identical as respective bunches open at different times of the year. Thus to recognize the distribution of two-monthly rainfall would be useful in this study.

Let JF, MA, MJ, JA, SO and ND denote the cumulative rainfall during January/February, March/April, May/June, July/August, September/October and November/December respectively of the preceding year. From the W-statistics and the normal probability plot in the Proc Univariate (SAS Institute Inc.), the distribution of MA, SO and ND were found to be approximately normal. The distributions of JF and JA were skewed to right. The distribution of MJ and MA seemed to be complex. The cumulative probability density functions were drawn to obtain probabilities for specific events of the variables. The mean $(x)$, standard deviation (s), five quartiles, $Q_{100}$ (maximum), $Q_{75}, Q_{50}$ (medium), $Q_{25}, Q_{0}$ (minimum) and the probability of rain exceeding the mean, $P_{r}$ (rain $>x$ ), of the six variables are given in Table 2 . The mean and other statistics were highest in SO while these were lowest in JF. An alternative approach is to fit normal distribution using a suitable transformation or gamma distribution (Diwakara, 1973) which will be discussed in a subsequent study. 
Table 2. Statistics of Bi-Monthly Cunulative Rainfall

\begin{tabular}{lrrrrrr}
\hline & JF & MA & MJ & JA & SO & ND \\
\hline X & 81.4 & 283.3 & 332.6 & 122.5 & 382.6 & 357.1 \\
S & 73.6 & 154.8 & 136.4 & 80.2 & 146.6 & 160.9 \\
Q100 & 298.6 & 871.3 & 693.1 & 366.0 & 690.6 & 661.7 \\
Q75 & 119.1 & 360.7 & 433.1 & 187.8 & 499.9 & 422.9 \\
Q50 & 75.4 & 240.6 & 318.0 & 98.9 & 363.2 & 332.0 \\
Q25 & 18.3 & 183.1 & 224.4 & 58.4 & 287.8 & 248.5 \\
Q0 & 0.0 & 87.5 & 74.4 & 25.9 & 97.5 & 0.0 \\
Pr (rain > x) & 0.451 & 0.456 & 0.428 & 0.419 & 0.453 & 0.452
\end{tabular}

\section{Degree of Influence of Bi-Monthly Rainfall}

The plot of yield vs JF, MA, MJ, JA, SO and ND are shown in Figures 1 (a) to I(f) respectively.

These graphical models indicate the uncertainty of the relationship between rainfall and yield. The correlatiion coefficients between yield and rainfall during the six sub-periods along with the $r_{m}$ for the seven yearly groups are given in Table 3 .

Table 3. Values of $r$ Between Yield and Two Monthly Rainfall in the Year Prior to Harvest

\begin{tabular}{|c|c|c|c|c|c|c|}
\hline $\begin{array}{l}\text { Year } \\
\text { Group }\end{array}$ & $\mathrm{JF}$ & MA & MJ & $\mathrm{JA}$ & SO & ND \\
\hline $69-83$ & 0.354 & 0.331 & 0.293 & 0.292 & -0.136 & $-0.710^{* *}$ \\
\hline $70-84$ & 0.428 & 0.363 & 0.364 & 0.228 & -0.010 & $-0.666^{* *}$ \\
\hline $71-85$ & $0.529 *$ & 0.485 & 0.342 & 0.204 & -0.098 & $-0.543^{*}$ \\
\hline $72-86$ & 0.457 & $0.503 *$ & 0.148 & 0.161 & -0.282 & $-0.564^{*}$ \\
\hline $73-87$ & 0.334 & $0.655^{* *}$ & 0.173 & 0.197 & -0.409 & -0.382 \\
\hline $74-88$ & 0.294 & $0.658 * *$ & 0.165 & 0.110 & -0.259 & -0.358 \\
\hline $75-89$ & 0.305 & $0.573^{*}$ & 0.112 & 0.290 & -0.248 & -0.374 \\
\hline \multicolumn{2}{|c|}{ mean } & 0.386 & $0.510^{*}$ & 0.228 & 0.212 & $-0.200 .514 *$ \\
\hline
\end{tabular}

The mean temperature along with the mean maximum and minimum temperatures of the bimonthly periods at $R E$ are also given in Table 4 . Figure 2 represents the plot of monthly mean (1969-1990) minimum and maximum temperatures.

Table 4. Minimum, Maximum and Mean Air Temperature $\left({ }^{\circ} \mathrm{C}\right)$ per day of Bi-Monthly Periods

\begin{tabular}{llccc}
\hline \multicolumn{2}{c}{ Period } & Minimum & Maximum & Mean \\
\hline Jan/Feb & (JF) & 20.8 & 30.4 & 25.6 \\
Mar/Apr & (MA) & 23.0 & 30.7 & 27.3 \\
May/Jun & (MJ) & 25.1 & 30.3 & 27.7 \\
Jul/Aug & (JA) & 24.9 & 29.7 & 27.3 \\
Sep/Oct & (SO) & 23.8 & 29.5 & 26.7 \\
Nov/Dec & (ND) & 22.3 & 29.1 & 25.7
\end{tabular}


Figure 1 (a) - Figure 1 (e) - Bi,monthly rainfall ( $\mathrm{mm}$ ) vs yield/ha (in thousands)
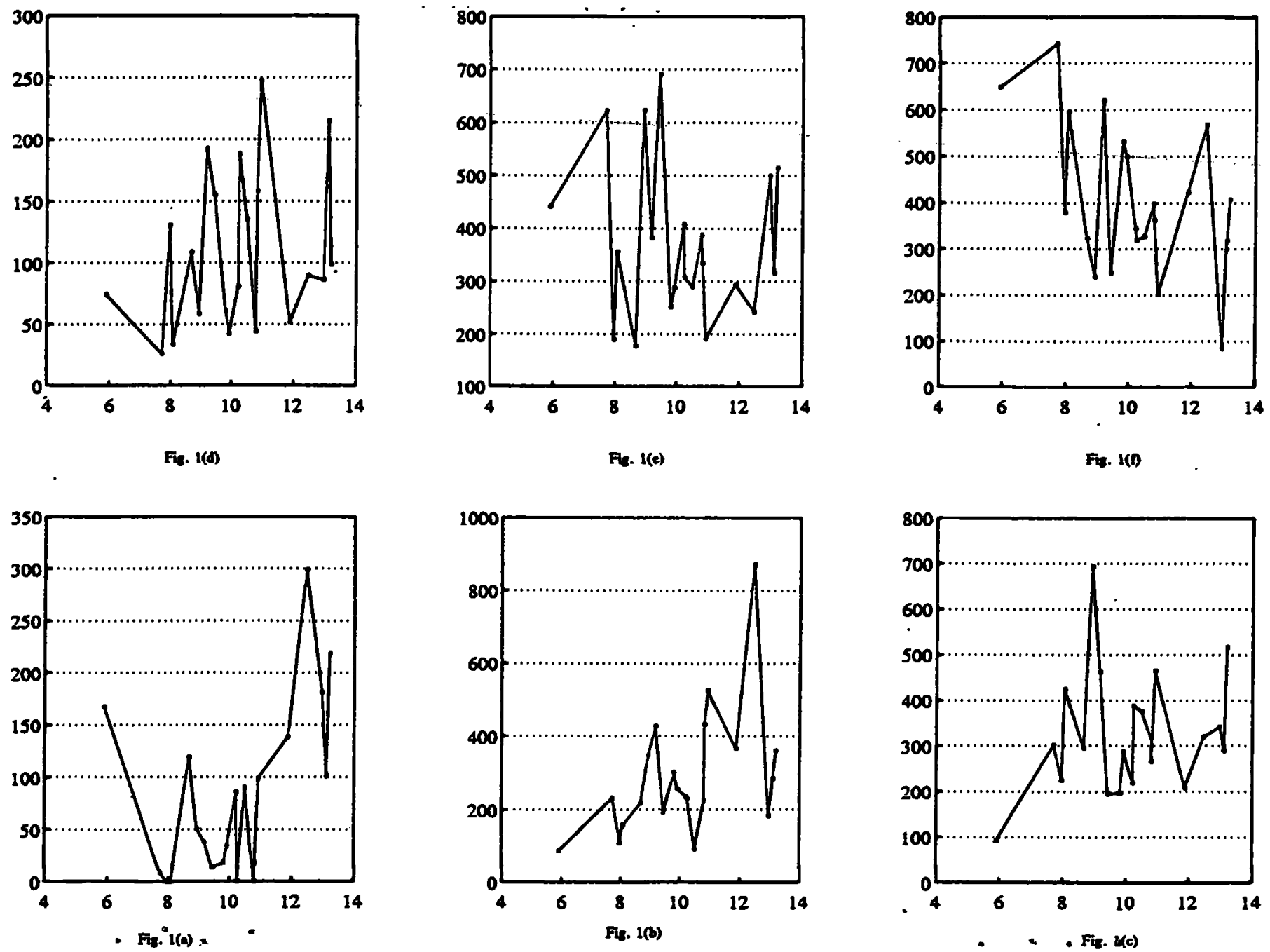
Figure 2 - Monthly maximum (*) and minimum (.) temperature

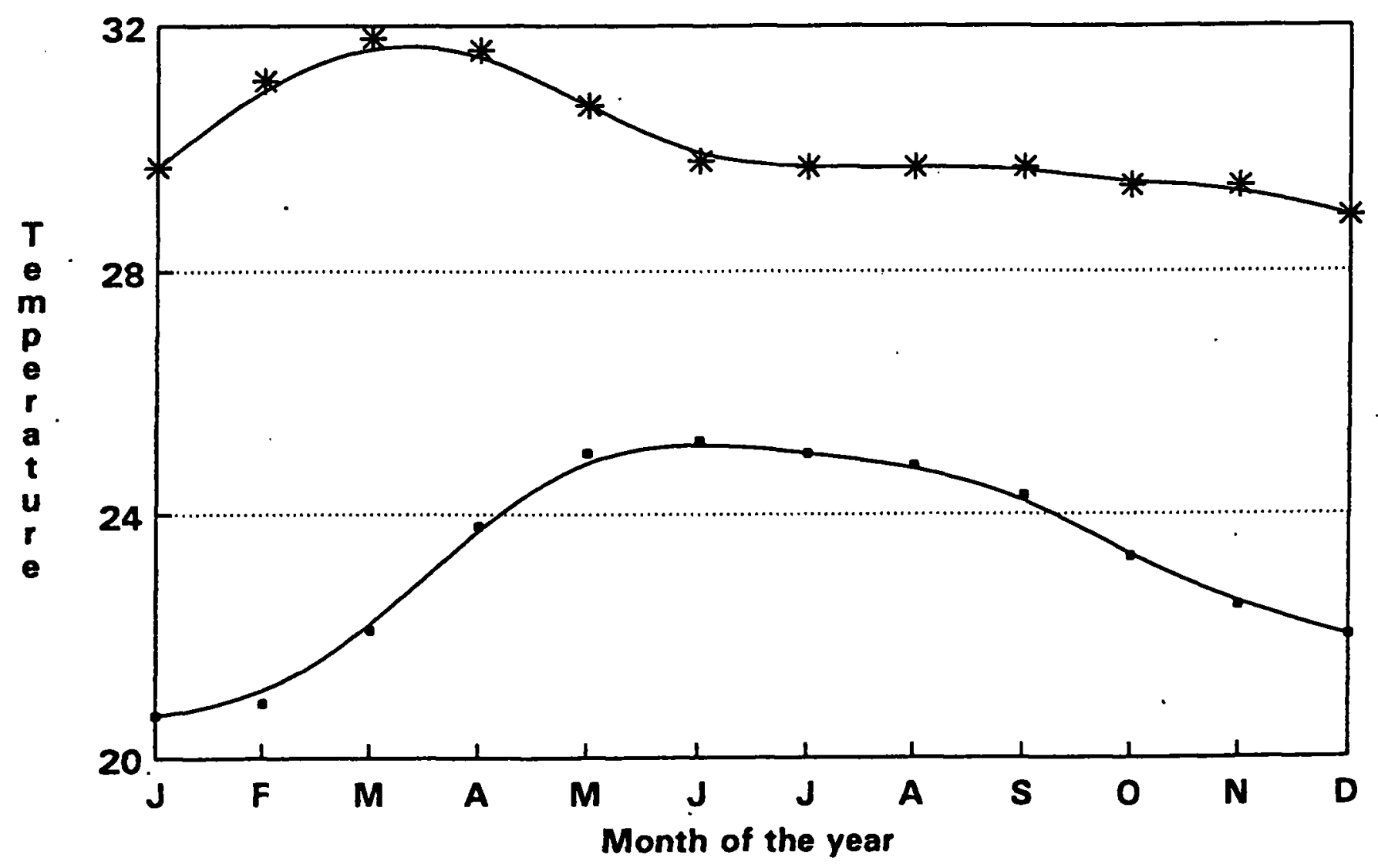


The $r_{m}$ between yield and cumulative rainfall during January/February was 0.386 which indicated a substantial influence of rainfall on yield. Adding JA2 into the linear models did not improve $\mathbf{R}^{2}$ in all the seven models fitted for seven yearly-groups. Between the six sub-periods the highest mean correlation between number of rainy days and the cumulative rainfall $\left(r=0.794^{* *}\right)$ was observed in January/February. This reveals that there is potential for increased yields with high rainfall and a greater number of rainy days during January/February. High yielding $(>11,000$ nuts $/ \mathrm{ha}$ ) years occurred when rainfall during January/February in the previous year exceeded 100 $\mathrm{mm}$ [Fig. 1 (a)] which was higher than the mean rainfall in this period $(81.4 \mathrm{~mm})$. The probability of rainfall intensity exceeding $100 \mathrm{~mm}$ during this period was 0.335 . Thus the beneficial effect on yield wherever observed was unlikely to be due to rainfall alone.

The relatively clear sky of January/February allows a higher incidence of solar radiation on the palms, increasing the evaporative demand. This condition is favourable to palms as long as there is an uninterrupted supply of soil water. In this instance, it would appear that such environmental conditions are facilitated by the high soil water reserves from the north-east monsoon rains that generally occur in the October/November period of the previous year. If soil water reserves were not available, the palms would respond favourably to applied water (irrigation) during this period. The data in this study are however inadequate to quantitatively test validity of this hypothesis.

\section{March/April (MA)}

The $\mathrm{r}_{\mathrm{m}}$ between yield and cumulative precipitation during March/April was reasonably high $\left(0.510^{*}\right)$ and significant. When quadratic models were fitted to the seven yearly-groups, separately $R^{2}$ values were not improved, which indicates that the cumulative precipitation is all used by palms beneficially towards increasing yield. The coefficients of JF were always higher than the coefficients of MA in all linear models fitted to the seven yearly-groups. It was evident that the yield response to rainfall during January/February was more marked than during March/April.

Evaporative demand in the atmosphere may have been higher during the period March/April compared to January/February and as a result of the rate of water supply to the palms falling short of potential evapotranspiration, palms are likely to have undergone a period of soil water "stress" during the March/April period. There was also a statistically significant interaction betwcen the rainfall during the two periods. Most of the high yielding points in Fig. I(b) were below the precipitation line of $400 \mathrm{~mm}$, indicating that palms could tolerate around $400 \mathrm{~mm}$ in March/April was very low (0.192). It therefore, appears that the rainfall and soil water reserve together could not provide the evapotranspiration needs of the palms during this period. Given adequate water (through rainfall or supplementary irrigation) the palms may have responded with a further increase in yield.

\section{May/June (MJ)}

The $r$ values in May/June were very low and non-significant in all yearly-groups. However, when $\mathrm{MJ}^{2}$ was added into the linear regression models, $\mathrm{R}^{2}$ was improved considerably in all cases. The range of $R^{2}$ in the linear model was from 1.25 to 13.28 whereas the range of $R^{2}$ for the quadratic model was 22.50 to 36.97 . The $R^{2} \mathrm{~m}$ was increased from 6.10 to 29.57 . The two parameters in the quadratic model were either significant or near significant at the 5\% level. It was thus clear that 
crop response to rainfall during May/June was quadratic. The range of the maximum points calculated for yearly-groups varied from 410 to $463 \mathrm{~mm}$. This suggests that the rainfall in excess of $460 \mathrm{~mm}$ during the period May/June would have a depressing effect on yield. The period May/ June being wet with frequent showers, the high cloud cover, the lower levels of solar radiation and high RH in the atmosphere may have resulted in a lower evaporative demand despite an adequate supply of soil water. This probably sets an upper limit to productivity of palms by decreasing the rate of photosynthesis.

\section{July/August (JA)}

The correlations in July/August were also low in all periods and were statistically not significant. The $r_{m}$ was lowest (positive) during this period and fitting a quadratic or a parabolic model did not increase $\mathbf{R}^{2}$. Thus the precipitation during this period showed neither a depressing nor an increasing effect on yield implying that the effect of rainfall itself during July/August was minimum.

The above position could be due to a water surplus occuring during the previous two months which is available for use by palms beneficially under conditions of high levels of solar radiation and therefore high evaporative demand. Excess water supplied through small rainfall events during this period may have been lost by soil evaporation, favoured by the same environmental conditions and hence may not contribute to productivity of palms.

\section{September/October (SO)}

The $r$ values observed in the period of September/October were all negative and varied from -0.010 to -0.409 . The mean value was -0.206 . Many high rainfall points in Fig. 1 (e) resulted in lower yield. The $\mathrm{R}^{2}$ slightly improved with the square root models than with the quadratic models indicating that the adverse effect on yield due to heavy rain could be minimal.

\section{November/December (ND)}

The mean correlation coefficient observed during the period November to December was 0.514 and significant at $5 \%$ level. The highest value was -0.710 and the lowest value was -0.358 . All values were negative. These results clearly show that there were harmful effects due to high rainfall during the last two months of the year. Adding $\mathrm{ND}^{2}$ into the linear models did not improve $\mathbf{R}^{2}$. However, the two coefficients in the first four yearly groups were both negative indicating a parabolic relationship between yield and rainfall. However, in the other three groups, a quadratic relationship was observerd where the maximum points changed from 374 to 388 . These results show that the response pattern was again complex. It also clearly indicates the negative effect of higher rainfall probably due to an excess of water in the soil along with a drop in evaporative demand due to high cloud cover, low solar radiatiion etc. as in the case of May/June.

\section{Crop-Rainfall Model}

In order to identify to what extent these bi-monthly rainfall parameters influence yield variation, step-wise regression was used to select the most suitable parameters. It was then found that in all seven yearly-groups the model, yield = $\mathrm{f}\left(\mathrm{JF}, \mathrm{MA}, \mathrm{MAMJ}, \mathrm{ND}^{2}\right.$, JFn), where JFn was the number of rainy days during January/February, MAMJ was the product of MA and MJ and others were as defined above, was reasonably fitted uniformly to all yearly-groups. The F-values 
were all significant at the $1 \%$ level and all the coefficients were significant at least at $5 \%$ level except $\mathrm{JFn}$ on three occasions. The $\mathrm{R}^{2}$ values were $89.18 \%, 92.73 \%, 83.89 \%, 88.64 \%, 92.74 \%$, $92.06 \%$ and $86.14 \%$ and so $\mathrm{R}_{\mathrm{m}}^{2}$ was 89.34 . About $89 \%$ of yield fluctuation over time can therefore be explained by these variables which would be useful in predicting annual yield in a given area in the Low Country Intermediate Zone in Sri Lanka, on short-term basis.

\section{CONCLUSIONS}

The study showed the degree of effect of rainfall in two-monthly sub periods in the year prior to the harvest on coconut in the Low Country Intermediate Zone of Sri Lanka. The rain during January/February was the most influential and that of July/August was least influential. The rainfall during May/June had a depressing effect and the optimum rainfall for coconut palms during May/June was $450 \mathrm{~mm}$. High rainfall during September/October had discernible effects on yield while the high rainfall during November/December decreased yield.

The underlying factors to which are attributed the fluctuation in yield due to rainfall is complex and require a concerted and multidisciplinary approach by plant physiologists, agroclimatologists, and soil scientists to understand such mechanisms and formulate measures to alleviate detrimental effects. The impact of major climatic factors such as solar radiation and relative humidity should be studied along with rainfall. In addition, studying the effects of these factors on the six picks separately would also be usefull.

The study showed that about $89 \%$ of the variation in yield could be explained using a multiple regression model using the parameters of cumulative rainfall during the period January/February (JF), May/June (MJ), number of rainy days during January/February, product of rainfall during March/April and May/June (MAMJ) and the square of rainfall during November/December (ND2). This model would be useful in identifying the potential yield in an area of the Low Country Intermediate Zone of Sri Lanka. Further, developing weather based mathematical models would be useful in crop-simulation studies.

\section{ACKNOWLEDGEMENTS}

We are grateful to Dr. R. Mahindapala, Director, CRI for his comments on this study. We are alsograteful to Vidya Jyothi Mr.P.R. Wijewardena and Vidya Jyothi Dr. C. R. Panabokke for their valuable comments on the manuscripts. Thanks are also due to Mr. D. T. Mathes, Head, Biometry Division and the staff of the Biometry for their kind assistance. A shortened version of this paper was presented by the senior author, at the Second International Symposium on Coconut Research and Development, 26-29 November, 1991, Kasaragoda, India.

\section{REFERENCES}

Abeywardene, V.\& Fernando,J. K. T. (1963). Seasonal variation in coconutCeylon Cocon, Quart. 14, 74-86.

Abeywardene, V. (1968). Forecasting coconut crops using rainfall data - A preliminary study Ceylon Cocon, Quart. 19, 161-176.

Child, R(1974), Coconuts. Tropical Agriculture Series. 335p, 2nd ed, Longmans Group Limited, London. 
Diwakara, A. Mooley. (1973). Gamma distribution probability for Asian summer monsoon monthly rainfall. Monthly Weather Review, 101 (2), 160-176.

Dootson, J., Ryder, K., Panit Ngangorantigarn, and Anupap Thirakul (1989) The Influence of climatic conditions on coconut yields in Thailand. Terminal Report of the OD A Coconut Development Project.

Peiris, T. S. G. (1989) Forecasting the crop yield of a coconut estate. CORD, 5 (2), 67 - 76.

Peiris, T. S. G. and Senevirtne, E. K. (1989). An Alternative apporach for analysis of data from a long term experiment. Cocos 7, $14-21$.

Pradada, Rao. G. S. L. H. V. (1986). Rainfall and yield in the Pilicode region, North Kerala.

Proceeding of PLACROSYM - V, 388 - 393.

Prasada, Rao. G. S. L. H. V.(1991). Agrometeorogical Aspects in Relation to Coconut Production, J. of Plantation Crops 19 (2), 120 - 126.

Smith, W.G.(1966). The relation between rainfall, soil water and yield of copra in a coconut estate in Trindad. Soil \& Fertilizer, 29 (6), 4 - 13.

SAS Institute Inc. (1985) SAS Procedures Guide for Personal Computers. 373p, Ver. 6, Cary, NC: SAS Institute Inc., USA. 